\begin{tabular}{|c|c|c|}
\hline 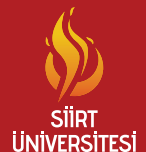 & $\begin{array}{c}\text { Türkiye Tarımsal Araştırmalar Dergisi } \\
\text { dergipark.org.tr/tutad }\end{array}$ & $\begin{array}{l}\text { Turk J Agric Res } \\
\text { 2019, 6(2): 193-198 } \\
\text { ○ TÜTAD } \\
\text { ISSN: 2148-2306 } \\
\text { e-ISSN: 2528-858X }\end{array}$ \\
\hline Bilimin Isüunda & Araştırma Makalesi / Research Article & doi: 10.19159/tutad.524099 \\
\hline
\end{tabular}

\title{
ANOM ve ANOMTR Testlerinin Performansları Bakımından Karşılaştırılması
}

\author{
Soner YİĞíT* \\ Çanakkale Onsekiz Mart Üniversitesi, Ziraat Fakültesi, Zootekni Bölümü, Çanakkale, TÜRKIYYE
}

\begin{tabular}{l}
\hline \multicolumn{1}{c}{ Geliş Tarihi/Received: $07.02 .2019 \quad$ Kabul Tarihi/Accepted: 19.06 .2019} \\
\hline ORCID ID \\
(D) orcid.org//0000-0002-2899-2246 \\
"Sorumlu Yazar/Corresponding Author: soneryigit@comu.edu.tr
\end{tabular}

Öz: Bu çalışmada, tek yönlü Ortalamaların Analizi (ANOM) ve Transforme Edilmiş Ranklara Dayalı Ortalamaların Analizi (ANOMTR) testleri varyansları homojen normal olmayan dağılımlarda 1. tip hata olasılığı ve testin gücü bakımından karşılaştırılmışıı. Yapılan 100000 simülasyon denemesi sonucunda, dikkate alınan deneme koşulları ne olursa olsun ANOMTR testi bakımından gerçekleşen 1. tip hata olasılıkları \% 4.50-5.50 içinde kalmıştır. Ancak ANOM testi bakımından gerçekleşen 1. tip hata olasılıklarının genel olarak bu sınırlar içerisinde kalmadığı görülmüştür. ANOM testinin dağılımın eğriliğinden ziyade, dikliğinden oldukça olumsuz etkilendiği tespit edilmiş̧ir. Varyanslar homojen olduğu sürece, dağılımın şekli ve tekerrür sayısı ne olursa olsun ANOMTR testi oldukça güvenilir sonuçlar vermiştir.

Anahtar Kelimeler: ANOM, ANOMTR, 1. tip hata, testin gücü, simülasyon

\section{Comparison of ANOM and ANOMTR Tests with Regard to Performances}

\begin{abstract}
In this study, one-way ANOM (Analysis of Means) and ANOMTR (Analysis of Means Based on Transformed Ranks) tests were compared in non-normal distributions with homogeneous variances in terms of the Type I error rate and test power. As a result of 100.000 simulation experiments conducted, regardless of the experimental conditions considered, actual Type I error rates occurred in ANOMTR was within the limits of 4.50-5.50\%. However, it was observed that actual Type I error rates occurred in ANOM test was generally not within these limits. The ANOM test was found to be affected quite negatively by the kurtosis rather than the skewness of the distribution. As long as the variances were homogeneous, the ANOMTR test has given very reliable results regardless of the shape of the distribution and the number of replications.
\end{abstract}

Keywords: ANOM, ANOMTR, type I error rate, test power, simulation

\section{Giriş}

ANOM, bağımsız grup ortalamalarını genel ortalama ile karşılaştırmak amacıyla kullanılan istatistiksel bir testtir (Nelson ve ark., 2005; Mendeş ve Yiğit, 2013). Grup karşılaştırmalarında, Varyans Analizi (ANOVA) Tekniği'ne alternatif olarak düşünülebilir (Dudewicz ve Nelson, 2003). ANOM testi de ANOVA'da olduğu gibi hataların normal dağılması ve varyansların homojenliği varsayımları altında geliştirilmiştir (Bakir, 1989; Nelson ve Dudewicz, 2002). Ayrica ANOM testi, varyansların homojenliğinin test edilmesinde (Bernard ve Wludyka, 2001), oran (Nelson ve ark., 2005), korelasyon (Rao ve Kumar, 2002) ve regresyon katsayılarının (Rao ve Deva Raaj, 2006) karşılaştırmasında ve çoklu karşılaştırma testi (genel ortalama ile) (Mendeş ve Yiğit, 2018) olarak da kullanılmaktadır. Grafiksel bir metot olmasından dolayı, sonuçların anlaşılması ve yorumlanması 
oldukça basittir. Aynı zamanda ANOM grafikleri, grup ortalamaları arasındaki farkın istatistiksel önemliliği yanında, pratik önemliliği hakkında da bilgi vermektedir (Nelson, 1983; Nelson ve ark., 2005, Yiğit ve Mendeş, 2017).

Mendeș ve Yiğit (2013), yaptıkları detaylı bir simülasyon çalışması ile ANOM testinin grup karşılaştırmalarındaki performansını ortaya koymuşlardır. Dikkate alınan deneme koşullarının tamamında ANOVA ile neredeyse aynı sonuçları verdiği rapor edilmiştir. ANOM testi'nin de ANOVA'da olduğu gibi normallik ve varyansların homojenliği varsayımlarının yerine gelmemesinden olumsuz etkilendiğini bildirmişlerdir. Bakir (1989), yaptığ1 bir çalışmada, ANOM testinin ranklara dayalı parametrik olmayan bir karşılığını (ANOMR) geliştirmiştir. Ancak bu testin sadece belirli deneme koşullarında kullanılabildiği dikkati çekmiştir. Nelson ve ark. (2005) ANOM üzerine yazdıkları kapsamlı kitaplarında, Bakir'in (1989) önerdiği yaklaşımı geliştirip (ANOMTR), herhangi bir kisitlama olmadan kullanılabilir hale getirmişlerdir.

Parametrik olmayan testler, bütün varsayımlardan bağımsız değildir. Özellikle varyansların homojen olmamasından parametrik olmayan testler de ciddi derecede olumsuz etkilenmektedirler. $\mathrm{Bu}$ çalışma; ANOM ve ANOMTR yöntemlerini varyansları homojen, ancak normal olmayan dağılımlardan alınan küçük hacimli $\quad(\mathrm{n} \leq 10)$ grup karşılaştırmalarında performansları bakımından incelemek amaciyla yürütülmüştür. $\mathrm{Bu}$ amaçla, söz konusu testler tek faktörlü deneme düzenlerinde kapsamlı bir simülasyon çalışmasıyla karşılaştırılmışlardır.

\section{Materyal ve Yöntem}

$\mathrm{Bu}$ çalışmanın materyalini $\mathrm{g} \& \mathrm{~h}$ dağılımından (Hoaglin, 1985) üretilmiș tesadüf sayıları oluşturmuştur. g\&h dağılımından sayı üretmek için, Standart Normal (Z) dağılımdan üretilen sayılara Eşitlik 1 ve 2'de verilen transformasyonlar uygulanır.

$$
\begin{aligned}
& \mathrm{g} \neq 0 \text { ise, } \mathrm{X}=\frac{\exp (\mathrm{gZ})-1}{\mathrm{~g}} \exp \left(\frac{\mathrm{hZ}^{2}}{2}\right) \\
& \mathrm{g}=0 \text { ise, } \mathrm{X}=\mathrm{Z} \exp \left(\frac{\mathrm{hZ}^{2}}{2}\right)
\end{aligned}
$$

g\&h dağılımında, g eğriliğgi/çarpıklığ (skewness), h ise dikliği/basıklığı (kurtosis) kontrol etmektedir. $\mathrm{g}=\mathrm{h}=0$ ise $\mathrm{g} \& \mathrm{~h}$ dağılımı, standart normal dağılıma eşittir. $g$ ve $h$ değerlerini değiştirerek farklı şekillere sahip dağılımlar elde edilebilmektedir.

$\mathrm{Bu}$ çalıșmada ANOM ve ANOMTR testleri, dağılım şekli (Şekil 1), etki büyüklüğü $(\delta)$, grup sayısı (k) ve tekerrür sayısı (n) gibi farklı deneme koşulları altında 1 . tip hata olasılığı $(\alpha)$ ve testin gücü (1- $\beta)$ bakımından karşılaştırılmışlardır. Dikkate alınan deneme koşullarının tamamında deneme başında kararlaştırılan 1. tip hata olasılığ \% 5.00'dır. Söz konusu testlerin gerçekleșen 1. tip hata olasılıkları, grupların alındıkları populasyonların ortalamaları arasında fark yok iken, 100000 simülasyon denemesi sonucunda

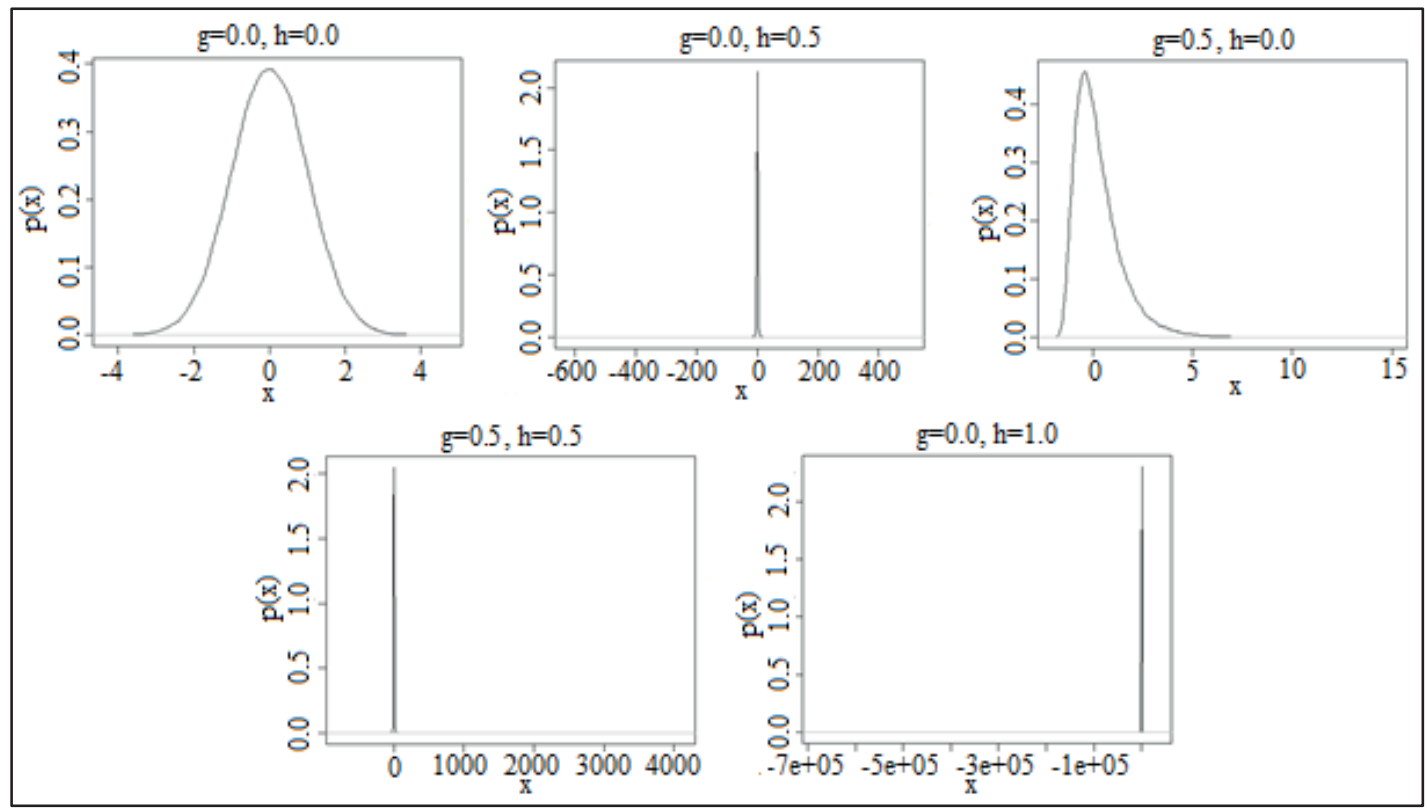

Şekil 1. Çalışmada dikkate alınan g\&h dağılımları 
reddedilen $\mathrm{H}_{0}$ hipotezi sayısının simülasyon sayısına bölünmesi ile elde edilmiştir. Testin gücü değerlerini hesaplamak için ise karşılaştırılan gruplardan rastgele bir tanesindeki gözlem değerlerinin hepsine sabit bir sayı $(\delta)$ eklenmiştir. Daha sonra reddedilen $\mathrm{H}_{0}$ hipotezi sayısı simülasyon sayısına bölünerek testlerin güç değerleri elde edilmiştir. Dikkate alınan deneme koşulları Tablo 1'de topluca verilmiştir.

Çalışmadaki simülasyon denemeleri R-Project (Anonymous, 2018) programlama diliyle yazılmış programlar ile yapılmıştır.

Tablo 1. Çalışmada dikkate alınan deneme koşulları

\begin{tabular}{lc}
\hline Dağılım & $\mathrm{g}=0.0, \mathrm{~h}=0.0 ; \mathrm{g}=0.5, \mathrm{~h}=0.0 ; \mathrm{g}=0.0, \mathrm{~h}=0.5 ; \mathrm{g}=0.5, \mathrm{~h}=0.5 ; \mathrm{g}=0.0, \mathrm{~h}=1.0$ \\
\hline Grup sayısı $(\mathrm{k})$ & 3,4 ve 5 \\
\hline Tekerrür sayısı $(\mathrm{n})$ & $3,4, \ldots, 10$ \\
\hline Etki büyüklüğ̈ $(\delta)$ & 0.00 ve 1.50 \\
\hline Simülasyon sayısı & 100000 \\
\hline
\end{tabular}

\section{1. İstatistiksel testler}

\subsubsection{ANOM testi}

ANOM testinde üst (UDL) ve alt (LDL) olmak üzere iki karar sınırı bulunmaktadır. $\mathrm{Bu}$ karar sınırları dışına çıkan grup ortalamalarının genel ortalamadan, dolayısıyla da en az başka bir grubun ortalamasından istatistiksel olarak farklı olduğu sonucuna varılır (Şekil 2 ve Şekil 3). Karar sınırları hesaplanırken tekerrür sayıları eşit ise Eşitlik 3 ve 4'ten, eşit değil ise Eşitlik 5 ve 6'dan yararlanılmaktadır.

$$
\begin{aligned}
& \mathrm{UDL}=\overline{\mathrm{Y}}_{. .}+\mathrm{h}(\alpha ; \mathrm{k}, \mathrm{N}-\mathrm{k}) \sqrt{\mathrm{HKO}} \sqrt{\frac{\mathrm{k}-1}{\mathrm{~N}}} \\
& \mathrm{LDL}=\overline{\mathrm{Y}}_{. .}-\mathrm{h}(\alpha ; \mathrm{k}, \mathrm{N}-\mathrm{k}) \sqrt{\mathrm{HKO}} \sqrt{\frac{\mathrm{k}-1}{\mathrm{~N}}} \\
& \mathrm{UDL}=\overline{\mathrm{Y}}_{. .}+\mathrm{m}(\alpha ; \mathrm{k}, \mathrm{N}-\mathrm{k}) \sqrt{\mathrm{HKO}} \sqrt{\frac{\mathrm{N}-n_{i}}{\mathrm{~N} n_{i}}} \\
& \mathrm{LDL}=\overline{\mathrm{Y}}_{. .}-\mathrm{m}(\alpha ; \mathrm{k}, \mathrm{N}-\mathrm{k}) \sqrt{\mathrm{HKO}} \sqrt{\frac{\mathrm{N}-\mathrm{n}_{\mathrm{i}}}{\mathrm{Nn_{i }}}}
\end{aligned}
$$

Eşitliklerde, $\bar{Y}_{. .}$genel ortalamay1; $h$ ve $\mathrm{m}$, ANOM kritik tablo değerini; $\alpha$, önem seviyesini; $\mathrm{k}$, grup sayısın1; $\mathrm{N}$, toplam gözlem sayısın1; $n_{i}$, tekerrür sayısını; HKO, hata kareler ortalamasını göstermektedir (Nelson ve ark., 2005).

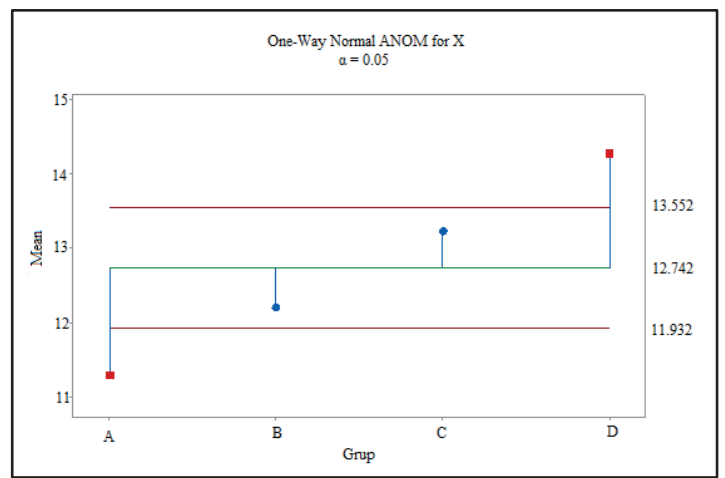

Şekil 2. Tekerrür sayıları eşit olduğunda ANOM grafiği

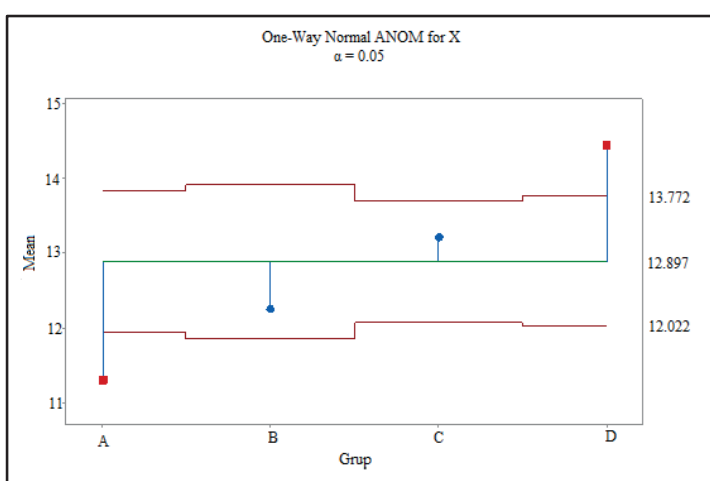

Şekil 3. Tekerrür sayıları eşit olmadığında ANOM grafiği

\subsubsection{ANOMTR testi}

ANOMTR testi, transforme edilmiş ranklara dayalı ANOM testidir (Nelson ve ark., 2005). ANOMTR testi uygulanırken aşağıdaki adımlar izlenmelidir

1- Bütün veriler bir araya getirilip, grup fark1 gözetilmeden rank $\left(R_{i j}\right)$ verilir.

2-Rank verilmiş verilere Eşitlik 7'deki gibi transformasyon uygulanır.

$$
\mathrm{E}_{\mathrm{ij}}=\Phi^{-1}\left[0.5+\mathrm{R}_{\mathrm{ij}} /(2 \mathrm{~N}+1)\right]
$$

Eşitlikte $\Phi^{-1}$, standart normal dağılım fonksiyonunun tersini; $\mathrm{R}_{\mathrm{ij}}$, orijinal verilerin rank verilmiş halini; $N$, toplam gözlem sayısını göstermektedir.

3- Son olarak transforme edilmiş ranklar $\left(E_{i j}\right)$ üzerinden klasik ANOM yöntemi uygulanır (Nelson ve ark., 2005).

\section{Bulgular ve Tartıșma}

Çalışmada dikkate alınan bütün deneme koşulları için gerçekleşen 1. tip hata olasılıkları Tablo 2-6'da dağılımlara göre ayrı ayrı, testlerin güç değerleri ise Şekil 4'te toplu olarak verilmiştir. ANOM ve ANOMTR testleri 1. tip hata olasılı̆̆ bakımından 
Tablo 2. $\mathrm{g}=0.0, \mathrm{~h}=0.0$ olduğunda gerçekleşen 1 . tip hata olasılıkları

\begin{tabular}{lcccccc}
\hline & \multicolumn{2}{c}{$\mathrm{k}=3$} & \multicolumn{2}{c}{$\mathrm{k}=4$} & \multicolumn{2}{c}{$\mathrm{k}=5$} \\
\hline $\mathrm{k}$ & ANOM & ANOMTR & ANOM & ANOMTR & ANOM & ANOMTR \\
\hline 3 & 4.90 & 4.59 & 5.11 & 4.95 & 4.96 & 5.42 \\
4 & 4.89 & 4.64 & 4.92 & 4.74 & 5.00 & 5.06 \\
5 & 4.86 & 4.60 & 5.22 & 4.96 & 5.00 & 4.92 \\
6 & 5.08 & 4.89 & 4.92 & 4.84 & 5.00 & 4.92 \\
7 & 4.96 & 4.87 & 5.02 & 4.84 & 5.02 & 4.99 \\
8 & 4.88 & 4.64 & 5.04 & 4.92 & 4.89 & 4.99 \\
9 & 5.11 & 5.15 & 4.92 & 4.94 & 5.03 & 5.05 \\
10 & 4.98 & 4.85 & 4.99 & 4.77 & 4.98 & 4.95 \\
\hline
\end{tabular}

Tablo 3. $\mathrm{g}=0.0, \mathrm{~h}=0.5$ olduğunda gerçekleşen 1 . tip hata olasılıkları

\begin{tabular}{lcccccc}
\hline & \multicolumn{2}{c}{$\mathrm{k}=3$} & \multicolumn{2}{c}{$\mathrm{k}=4$} & \multicolumn{2}{c}{$\mathrm{k}=5$} \\
\hline $\mathrm{k}$ & ANOM & ANOMTR & ANOM & ANOMTR & ANOM & ANOMTR \\
\hline 3 & $2.78^{*}$ & 4.52 & $3.36^{*}$ & 5.13 & $3.96^{*}$ & 5.49 \\
4 & $2.68^{*}$ & 4.68 & $3.24^{*}$ & 4.79 & $4.30^{*}$ & 4.94 \\
5 & $2.82^{*}$ & 4.73 & $3.56^{*}$ & 4.89 & $4.36^{*}$ & 4.84 \\
6 & $2.86^{*}$ & 4.78 & $3.61^{*}$ & 4.88 & 4.60 & 4.95 \\
7 & $2.93^{*}$ & 4.80 & $3.74^{*}$ & 4.94 & 4.84 & 4.88 \\
8 & $3.11^{*}$ & 5.04 & $3.74^{*}$ & 4.84 & 4.71 & 4.98 \\
9 & $3.08^{*}$ & 4.90 & $3.82^{*}$ & 4.90 & 4.84 & 4.94 \\
10 & $3.22^{*}$ & 4.87 & $3.76^{*}$ & 4.91 & 5.05 & 5.13 \\
\hline
\end{tabular}

*: Bradley (1978) sınırları (\% 4.50-5.50) dışına çıkanlar

Tablo 4. $\mathrm{g}=0.0, \mathrm{~h}=0.1$ olduğunda gerçekleşen 1 . tip hata olasılıkları

\begin{tabular}{lcccccc}
\hline & \multicolumn{2}{c}{$\mathrm{k}=3$} & \multicolumn{2}{c}{$\mathrm{k}=4$} & \multicolumn{2}{c}{$\mathrm{k}=5$} \\
\hline $\mathrm{k}$ & ANOM & ANOMTR & ANOM & ANOMTR & ANOM & ANOMTR \\
\hline 3 & $1.67^{*}$ & 4.56 & $2.40^{*}$ & 5.10 & $3.36^{*}$ & 5.41 \\
4 & $1.62^{*}$ & 4.82 & $2.24^{*}$ & 4.72 & $3.59^{*}$ & 5.08 \\
5 & $1.69^{*}$ & 4.79 & $2.33^{*}$ & 4.85 & $3.72^{*}$ & 5.03 \\
6 & $1.56^{*}$ & 4.74 & $2.45^{*}$ & 4.76 & $3.67^{*}$ & 4.67 \\
7 & $1.64^{*}$ & 4.84 & $2.51^{*}$ & 4.88 & $3.66^{*}$ & 4.82 \\
8 & $1.55^{*}$ & 4.83 & $2.53^{*}$ & 4.95 & $3.67^{*}$ & 4.95 \\
9 & $1.63^{*}$ & 4.97 & $2.44^{*}$ & 5.06 & $3.65^{*}$ & 4.87 \\
10 & $1.66^{*}$ & 4.82 & $2.57^{*}$ & 4.72 & $3.83^{*}$ & 4.82 \\
\hline
\end{tabular}

*: Bradley (1978) sınırları (\% 4.50-5.50) dışına çıkanlar

karşılaştırılırken, Bradley (1978)'in \% 4.50-5.50 sınırları dikkate alınmıştır. Bu sınırlar dışına çıkan 1. tip hata olasılıkları verilen tablolarda koyu olarak yazılmıştır.

Standart Normal Dağılım'dan $(g=0.0, \mathrm{~h}=0.0)$ alınan grup ortalamaları karşılaştırılırken tekerrür sayıs1 ve grup sayısı ne olursa olsun her iki testin de gerçekleşen 1. tip hata olasılıkları \% 4.50-5.50 arasında olduğu görülmüştür (Tablo 2).

Karşılaştırılan gruplar, simetrik ve dik ( $\mathrm{g}=0.0$, $\mathrm{h}=0.5$ ) bir dağılımdan alındığında ANOMTR testinin deneme düzeni ne olursa olsun 1. tip hata olasılığını \% $\quad 5.00 \quad$ seviyesinde koruduğu görülmüştür. Ancak ANOM yöntemi neredeyse dikkate alınan deneme koşullarının tamamında $(\mathrm{k}=5$ ve $\mathrm{n}>5$ hariç) 1. tip hata olasılığını koruyamamıştır (Tablo 3).

Simetrik ve aşırı dik $(\mathrm{g}=0.0, \mathrm{~h}=1.0)$ bir populasyondan alınan gruplar karşılaştırılırken
ANOM testi bakımından gerçekleşen 1. tip hata olasılıkları hiçbir koşulda Bradley (1978) sınırları içerisine giremezken, ANOMTR testi bakımından gerçekleşen 1. tip hata olasılıklarının dikkate alınan deneme koşullarının tamamında söz konusu sınırlar içerisinde yer aldığg görülmüştür (Tablo 4).

Eğri ve dik ( $\mathrm{g}=0.5, \mathrm{~h}=0.5)$ bir dağılım gösteren populasyonlardan alınan grupların karşılaştırılmalarında ANOMTR testi 1.tip hata olasılığını $\% \quad \begin{array}{llll}5.00 & \text { seviyesinde }\end{array}\left(\begin{array}{ll}\% & 4.50-5.50\end{array}\right.$ aralığında) korurken, ANOM testinin neredeyse ( $k=5$ ve $n>4$ hariç) hiç koruyamadığ 1 görülmüştür (Tablo 5).

Karşılaştırılan grupların, eğri ve hafif dik $(\mathrm{g}=0.5, \quad \mathrm{~h}=0.0)$ bir dağılım gösteren populasyonlardan alındığında ANOMTR testinin bütün deneme koşullarında, ANOM testinin ise $\mathrm{k}>3$ olduğunda 1. tip hata olasılığını Bradley (1978) sınırları içerisinde koruma bakımından oldukça başarılı olduğu görülmüştür. $\mathrm{Bu}$ durum ANOM 
Tablo 5. $\mathrm{g}=0.5, \mathrm{~h}=0.5$ olduğunda gerçekleşen 1. tip hata olasıllkları

\begin{tabular}{lcccccc}
\hline & \multicolumn{2}{c}{$\mathrm{k}=3$} & \multicolumn{2}{c}{$\mathrm{k}=4$} & \multicolumn{2}{c}{$\mathrm{k}=5$} \\
\hline $\mathrm{k}$ & ANOM & ANOMTR & ANOM & ANOMTR & ANOM & ANOMTR \\
\hline 3 & $2.72^{*}$ & 4.69 & $3.42^{*}$ & 5.06 & $4.16^{*}$ & 5.14 \\
4 & $2.69^{*}$ & 4.85 & $3.44^{*}$ & 4.82 & $4.43^{*}$ & 4.96 \\
5 & $2.68^{*}$ & 4.72 & $3.50^{*}$ & 4.88 & 4.76 & 4.98 \\
6 & $2.71^{*}$ & 4.87 & $3.65^{*}$ & 5.07 & 4.80 & 4.87 \\
7 & $2.67^{*}$ & 4.83 & $3.77^{*}$ & 5.03 & 4.95 & 4.94 \\
8 & $2.84^{*}$ & 5.03 & $3.70^{*}$ & 4.93 & 4.96 & 4.87 \\
9 & $2.91^{*}$ & 5.00 & $3.73^{*}$ & 4.92 & 5.03 & 5.06 \\
10 & $2.89^{*}$ & 4.76 & $3.63^{*}$ & 4.87 & 5.22 & 4.96 \\
\hline
\end{tabular}

*: Bradley (1978) sınırları (\% 4.50-5.50) dışına çıkanlar

Tablo 6. $\mathrm{g}=0.5, \mathrm{~h}=0.0$ olduğunda gerçekleşen 1 . tip hata olasılıkları

\begin{tabular}{lcccccc}
\hline & \multicolumn{2}{c}{$\mathrm{k}=3$} & \multicolumn{2}{c}{$\mathrm{k}=4$} & \multicolumn{2}{c}{$\mathrm{k}=5$} \\
\hline $\mathrm{k}$ & ANOM & ANOMTR & ANOM & ANOMTR & ANOM & ANOMTR \\
\hline 3 & $4.44^{*}$ & 4.77 & 4.81 & 5.04 & 5.37 & 5.42 \\
4 & $4.40^{*}$ & 4.72 & 4.79 & 4.83 & 5.17 & 4.85 \\
5 & $4.43^{*}$ & 4.91 & 4.68 & 4.74 & 5.17 & 4.83 \\
6 & $4.40^{*}$ & 4.80 & 4.69 & 4.74 & 5.15 & 4.81 \\
7 & $4.46^{*}$ & 4.85 & 4.76 & 4.90 & 4.91 & 4.73 \\
8 & $4.46^{*}$ & 4.87 & 4.65 & 4.73 & 4.96 & 4.80 \\
9 & $4.49^{*}$ & 4.93 & 4.77 & 4.82 & 5.08 & 4.89 \\
10 & $4.48^{*}$ & 4.77 & 4.84 & 4.95 & 5.27 & 5.14 \\
\hline
\end{tabular}

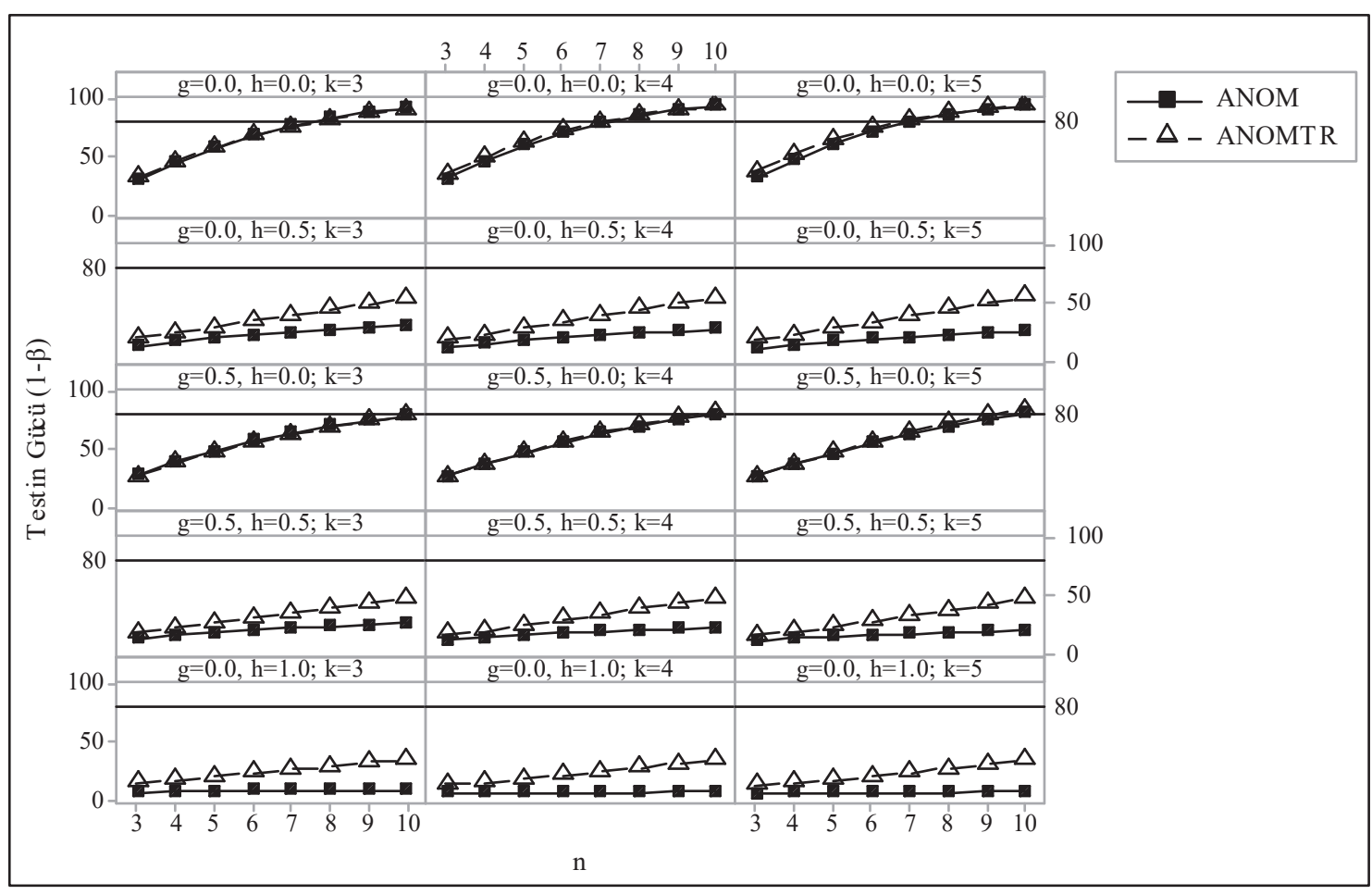

Şekil 4. Testlerin güç değerleri

testinin dağılımın simetrikliğinden ziyade dikliğinden ciddi derecede etkilendiğini göstermektedir. Buna karşın ANOMTR testinin ne dağglımın eğriliğinden ne de dikliğinden etkilendiği oldukça açıktır (Tablo 6).
Standart Normal Dağılım'dan (g=0.0 ve h=0.0) alınan gruplar karşılaştırılırken her iki test bakımında da gerçekleşen güç değerlerinin birbirine çok yakın olduğu, ancak $\mathrm{n}>6$ olduğunda \% 80.00 'lik güç değerine ulaşabildikleri görülmüştür. 
Bunun dişında neredeyse $(\mathrm{g}=0.5, \mathrm{~h}=0.0$ iken $\mathrm{n}>9$ hariç) hiçbir deneme koşulunda \% 80.00'lık güç değerini yakalayamamışlardır (Şekil 2). Testin gücü, etki büyüklügü ve örnek hacmi ile doğrudan ilişkili olduğundan dolayı, istenilen güç değerine göre örnek hacminin deneme başında doğru bir şekilde belirlenmesi gerekmektedir. Bu çalışmanın sonuçları normallikten sapmaların artması durumunda istenilen güç değerine ulaşabilmek için küçük hacimli $(\mathrm{n}<10)$ örneklerle çalıșılmaması gerektiğini göstermektedir.

\section{Sonuçlar}

Uygulamada yapılan araştırmaların büyük bir kısmında grup karşılaştırmalarıyla ilgilenilmektedir. Bu amaçla da ANOVA-F testine alternatif olan ANOM testi de giderek yaygınlaşmaya başlamıştır. $\mathrm{Bu}$ çalışmada da parametrik olmayan (dağılımdan bağımsız) ANOMTR testinin birçok deneme koşulundaki performansı ortaya konmuştur. Dikkate alınan deneme koşullarının tamamında dağılımın şeklinden etkilenmediği belirlenmiştir. Dolayısıyla aşırı eğri ve dik dağılımlardan alınan grupların karşılaştırılmasında ANOMTR testinden yararlanılabileceği görülmüştür.

ANOM ve ANOMTR testleri grafiksel yöntemler olduklarından dolayı sonuçların anlaşılması ve yorumlanması oldukça kolaydır. Ayrıca sadece grup karşılaştırmalarında değil, varyansların homojenliğinin test edilmesinde, oran, korelasyon ve regresyon katsayılarının karşılaştırılmasında ve çoklu karşılaştırma testi olarak da (genel ortalama ile) kullanılabilmektedirler.

Son yillarda, ANOM ve ANOMTR testleri SAS (Anonymous, 1999), Minitab 18 (Anonymous, 2017), JMP 12 (Anonymous, 2016) ve R-Project (Anonymous, 2018) gibi oldukça yaygın kullanılan istatistik paket programlara dâhil edilmiştir. Sonuç olarak, kullanımı giderek yaygınlaşan bu testlerin grup karşılaştırmalarında, birçok amaç için kullanılabileceği ve güvenilir sonuçlar elde edilip, çok basit yorumlanabileceği kanısına varılmıştır.

\section{Kaynaklar}

Anonymous, 1999. SAS Institute Inc., SAS OnlineDoc ${ }^{\circledR}$, Version 8, Cary, NC.
Anonymous, 2016. JMP®, Version 12., SAS Institute Inc., Cary, $\mathrm{NC}$

Anonymous, 2017. MINITAB 18, Statistical Software, State College, PA: Minitab, Inc.

Anonymous, 2018. R Core Team: R: A language and environment for statistical computing. R Foundation for Statistical Computing, Vienna, Austria.

Bakir, S.T., 1989. Analysis of means using ranks. Communications in Statistics-Simulation and Computation, 18(2): 757-776.

Bernard, A.J., Wludyka, P.S., 2001. Robust I-sample analysis of means type randomization tests for variances. Journal of Statistical Computation and Simulation, 69(1): 57-88.

Bradley, J.V., 1978. Robustness?. British Journal of Mathematical and Statistical Psychology, 31(2): 144152.

Dudewicz, E.J., Nelson, P.R., 2003. Heteroscedastic analysis of means (Hanom). American Journal of Mathematical and Management Sciences, 23(1-2): 143-181.

Hoaglin, D.C. 1985. Summarizing shape numerically: The g-and-h distributions. In D. Hoaglin, F. Mosteller and J. Tukey (Eds.), Exploring data tables, trends, and shapes. New York: Wiley.

Mendeş, M., Yiğit, S., 2013. Comparison of ANOVA-F and ANOM tests with regard to type I error rate and test power. Journal of Statistical Computation and Simulation, 83(11): 2093-2104.

Mendeș, M., Yiğit, S., 2018. An alternative approach for multiple comparison problems when there are a large number of groups: ANOM technique. Journal of Animal \& Plant Sciences, 28(4): 1075-1079.

Nelson, P.R., 1983. The analysis of means for balanced experimental designs. Journal of Quality Technology, 15(1): 45-54.

Nelson, P.R., Dudewicz, E.J., 2002. Exact analysis of means with unequal variances. Technometrics, 44(2): 152-160.

Nelson, P.R., Wludyka, P.S., Copeland, K.A.F., 2005. The Analysis of Means: A Graphical Method for Comparing Means, Rates and Proportions. SIAM, Philadelphia.

Rao, C.V., Deva Raaj, V.J., 2006. ANOM for testing the equality of several intercepts in a k-sample regression model. Statistical Methods, 8(1): 60- 72.

Rao, C.V., Kumar, M.P., 2002. ANOM-type graphical methods for testing the equality of several correlation coefficients. Gujarat Statistical Review, 29: 47-56.

Yiğit, S., Mendeş, M., 2017. ANOM technique for evaluating practical significance of observed difference among treatment groups. International Journal of Agricultural Science Research, 6(1): 1-7. 